\title{
The Effect of Postoperative Use of Teriparatide Reducing Screw Loosening in Osteoporotic Patients
}

\author{
Jae Wook Kim, M.D., Seung Won Park, M.D., Ph.D., Young Baeg Kim, M.D., Myeong Jin Ko, M.D. \\ Department of Neurosurgery, Chung-Ang University Hospital, Seoul, Korea
}

Objective : The loosening of pedicle screws (PS) is one of the frequent problems of spinal surgery in the patients with osteoporosis. Previous studies had revealed that intermittent injection of teriparatide could reduce PS loosening by improving bone mass and quality when their patients took parathyroid hormone for a considerable duration before surgery. However, although the teriparatide is usually used after spine surgery in most clinical situations, there was no report on the efficacy of teriparatide treatment started after spine surgery. The purpose of this retrospective study was to examine the efficacy of teriparatide treatment started immediately after lumbar spinal surgery to prevent pedicle screw loosening in patients with osteoporosis.

Methods : We included 84 patients with osteoporosis and degenerative lumbar disease who underwent transforaminal interbody fusion and PS fixation and received parathyroid hormone or bisphosphonate (BP) postoperatively. They were divided into teriparatide group (daily injection of $20 \mu \mathrm{g}$ of teriparatide for 6 months, 33 patients, 172 screws) and BP group (weekly oral administration of $35 \mathrm{mg}$ of risedronate, 51 patients, 262 screws). Both groups received calcium (500 mg/day) and cholecalciferol (1000 IU/day) together. The screw loosening was evaluated with simple radiographic exams at 6 and 12 months after the surgery. We counted the number of patients with PS loosening and the number of loosened PS, and compared them between the two groups. Clinical outcomes were evaluated using visual analog scale (VAS) and Oswestry disability index (ODI) preoperatively, and at 12 months after surgery.

Results : There was no significant difference in the age, sex, diabetes, smoking, bone mineral density, body mass index, and the number of fusion levels between the two groups. The number of PS loosening within 6 months after surgery did not show a significant difference between the teriparatide group $(6.9 \%, 12 / 172)$ and the BP group $(6.8 \%, 18 / 272)$. However, during 6-12 months after surgery, it was significantly lower in the teriparatide group $(2.3 \%, 4 / 172)$ than the BP group $(9.2 \%, 24 / 272)(p<0.05)$. There was no significant difference in the number of patients showing PS loosening between the teriparatide and BP groups. The teriparatide group showed a significantly higher degree of improvement of the bone mineral density (T-score) than that of BP group $(p<0.05)$. There was no significant difference in the pre- and post-operative VAS and ODI between the groups.

Conclusion : Our data suggest that the teriparatide treatment starting immediately after lumbar spinal fusion surgery could reduce PS loosening compared to BP.

Key Words : Parathyroid hormone · Teriparatide · Spinal fusion.

- Received : July 20, 2017 •Revised : September 13, 2017 •Accepted : September 23, 2017

-Address for reprints : Seung Won Park, M.D., Ph.D.

Department of Neurosurgery, Chung-Ang University Hospital, 102 Heukseok-ro, Dongjak-gu, Seoul 06973, Korea

Tel : +82-2-6299-3190, Fax : +82-2-6299-2064, E-mail : nspsw@cau.ac.kr

This is an Open Access article distributed under the terms of the Creative Commons Attribution Non-Commercial License (http://creativecommons.org/licenses/by-nc/4.0) which permits unrestricted non-commercial use, distribution, and reproduction in any medium, provided the original work is properly cited. 


\section{INTRODUCTION}

Aging population has led to a subsequent rise in the prevalence of spinal fusion for degenerative spinal diseases in elderly patients with severe osteoporosis ${ }^{5,21)}$. According to the Korea Health Insurance Review and Assessment Service, Korea officially became an aging society with the elderly population (>65 years) rising from $9.88 \%$ in 2007 to $12.57 \%$ in 2014 . The number of spinal surgery cases during the same period grew by about $30 \%$, and $77.1 \%$ of the patients who received a spinal surgery were older than 50 years.

Patients with osteoporosis are often associated with reduced pullout strength and insertional torque, which are known to be related with pedicle screw (PS) loosening ${ }^{14,21,36,37)}$. However, despite the osteoporosis is well recognized as a highly important risk factor for PS loosening and considerable efforts are being made to overcome the problem, spinal fusion surgery remains a challenge in the elderly patients with osteoporo$\operatorname{sis}^{16,35)}$

Several methods have been developed to enhance PS stability during spinal fusion surgery in patients with low bone quality. Expandable pedicle screws have not only significantly increased pullout strength compared to conventional pedicle screws, but also significantly reduced PS loosening resulting in better clinical outcome ${ }^{6,25,45)}$. Further, PS augmentation using polymethylmethacrylate has been reported to increase the pullout strength of $\mathrm{PS}^{11,28)}$, reduce PS loosening, increase fusion rate, and improve clinical outcome in patients with osteoporosis ${ }^{41)}$. Use of cortical screws for lumbar spine or tricortical PS insertion at the S1 level is also used to increase pullout strength $^{12,26,43)}$.

Treating osteoporosis may increase PS stability by improving bone quality ${ }^{16,34,42)}$. The two most representative medications for osteoporosis are bisphosphonate (BP) and parathyroid hormone $(\mathrm{PTH})^{16,23)}$. BP is an anti-resorptive drug that acts as an osteoclast inhibitor ${ }^{10)}$. On the other hand, PTH is involved in a different mechanism increasing bone formation by stimulating osteoblastic activity ${ }^{22}$. Compared to BP, PTH is known to more effectively increase bone strength and bone mineral density (BMD) of the lumbar spine and to have a better fusion rate ${ }^{1,20,22,32)}$. Particularly, several studies have reported that teriparatide injection for 2 months before surgery led to higher fusion rate and reduced PS loosening than the patients group receiving BP orally, which showed the usefulness of teriparatide in spinal fusion surgery for osteoporotic patients $^{33,34)}$. Based on our experience, however, using teriparatide for several months prior to surgery was quite difficult in most cases. Nevertheless, there has not been a study examining whether the use of teriparatide starting with surgery can prevent PS loosening. Hence, we planned to investigate the effects of teriparatide starting with lumbar fusion surgery on the occurrence of PS loosening in the osteoporotic patients.

\section{MATERIALS AND METHODS}

\section{Patient}

A total of 345 patients underwent transforaminal lumbar interbody fusion (TLIF) for the degenerative lumbar diseases at our hospital between March 2012 and December 2015. We excluded 179 patients without osteoporosis, 59 patients who have been using teriparatide or BP previously for known osteoporosis, and 23 patients with spinal tumor, infection, or acute vertebral fractures. Finally, 84 patients were enrolled in the study. The BMD in the lumbar spine and femur neck was checked preoperatively and at one year after surgery using the Dual-energy x-ray absorptiometry (GE Lunar, Madison, WI, USA). And T-score lower than -2.5 at any one site were diagnosed with osteoporosis ${ }^{15,19)}$. Teriparatide was first recommended in patients with osteoporosis. Patients who refused to take teriparatide were advised to use BP. The patients were divided into teriparatide group $(n=33)$ and BP group $(n=51)$ based on postoperative administration of teriparatide or BP.

\section{Surgery}

All patients underwent TLIF using single capstone cage (Medtronic, Minneapolis, MN, USA) filled with autologous bone chips obtained from laminectomy and facetectomy. Two surgeons performed the surgeries using the same surgical procedures. The patients were instructed to wear a lumbar support brace for 3 months after surgery.

\section{Administration of teriparatide and BP}

The teriparatide group $(n=33)$ received subcutaneous injection of teriparatide $(20 \mu \mathrm{g}$; Forsteo, Eli Lilly, Indianapolis, IN, USA) every day for 6 months starting immediately after surgery, after 6 months of teriparatide administration, the drug 
was changed to risedronate $(35 \mathrm{mg}$; Actonel, Sanofi-Aventis Korea, Seoul, Korea). The BP group ( $n=51)$ took risedronate orally (35 mg; Actonel) once every week immediately after surgery for 12 months. All the patients in both groups orally took calcium (500 mg/day) and cholecalciferol (1000 IU/day; Dicamax D, Dalim Biotech, Seoul, Korea) once every day immediately after surgery.

\section{Radiographical and clinical evaluation}

To assess PS loosening, simple radiography was performed every month following surgery, and the incidences of PS loosening in the two groups were compared at 6 and 12 months

Table 1. Patient characteristics and changes in bone mineral density after 12 months

\begin{tabular}{|c|c|c|c|}
\hline & $\begin{array}{l}\text { Teriparatide } \\
\text { group }(n=33)\end{array}$ & $\begin{array}{l}\text { BP group } \\
(n=51)\end{array}$ & $p$-value \\
\hline Age (years) & $69.48 \pm 7.76$ & $66.75 \pm 6.46$ & 0.083 \\
\hline $\operatorname{Sex}(M: F)$ & $8: 25$ & $12: 39$ & 0.940 \\
\hline DM & 7 & 9 & 0.684 \\
\hline Smoking & 3 & 6 & 0.698 \\
\hline BMl & $23.85 \pm 3.14$ & $24.26 \pm 3.14$ & 0.556 \\
\hline $\begin{array}{l}\text { Extent of the } \\
\text { operation }\end{array}$ & & & 0.752 \\
\hline 1 level & 16 & 27 & \\
\hline 2 levels & 14 & 19 & \\
\hline 3 levels & 3 & 5 & \\
\hline \multicolumn{4}{|l|}{ Operative level } \\
\hline L3-4 & 2 & 3 & \\
\hline$\llcorner 4-5$ & 10 & 21 & \\
\hline L5-S1 & 4 & 3 & \\
\hline L2-3-4 & 1 & 1 & \\
\hline L3-4-5 & 4 & 6 & \\
\hline L4-5-S1 & 9 & 12 & \\
\hline L3-4-5-S1 & 3 & 5 & \\
\hline $\begin{array}{c}\text { BMD (T-score), } \\
\text { preoperative }\end{array}$ & $-3.09 \pm 0.49$ & $-2.94 \pm 0.39$ & 0.126 \\
\hline $\begin{array}{l}\text { BMD (T-score), } \\
12 \text { months } \\
\text { after surgery }\end{array}$ & $-2.61 \pm 0.55$ & $-2.68 \pm 0.44$ & 0.520 \\
\hline $\begin{array}{l}\text { BMD (T-score) } \\
\text { change for } \\
12 \text { months (\%) }\end{array}$ & $14.86 \pm 14.97$ & $8.55 \pm 11.43$ & 0.032 \\
\hline
\end{tabular}

BP : bisphosphonate, $\mathrm{M}$ : male, $\mathrm{F}$ : female, DM : diabetes mellitus, BMI : body mass index, BMD : bone mineral density after surgery. PS loosening was defined as the presence of at least $1 \mathrm{~mm}$ halo sign with radiolucent line surrounding the screw $^{7,34,40)}$. Two neurosurgeons performed radiological assessments, and PS loosening was diagnosed upon agreement by both surgeons. To compare the postoperative clinical outcomes, the visual analog scale (VAS; $0=$ no pain, $10=$ worst pain) and Oswestry disability index (ODI) were measured preoperatively and at 12 months postoperatively.

\section{Statistical analysis}

Statistical analysis was performed using SPSS for Windows version 20 (SPSS, Chicago, IL, USA). The independent t-test, chi-square test, and Fisher's exact test were performed with significance level set at $p<0.05$.

Table 2. VAS and ODI

\begin{tabular}{lrrc}
\hline & Teriparatide & BP & $p$-value \\
\hline Low back pain, preoperative & & & \\
VAS & $4.31 \pm 2.05$ & $4.51 \pm 1.72$ & 0.68 \\
ODI & $45.04 \pm 8.02$ & $44.91 \pm 6.42$ & 0.94 \\
Leg pain, preoperative & & & \\
VAS & $7.35 \pm 1.07$ & $7.24 \pm 0.78$ & 0.64 \\
Low back pain at 12 months & & & \\
VAS & $2.74 \pm 0.96$ & $3.09 \pm 1.34$ & 0.29 \\
ODI & $20.78 \pm 7.33$ & $21.29 \pm 8.18$ & 0.81 \\
Leg pain at 12 months & & & \\
VAS & $3.13 \pm 1.25$ & $3.34 \pm 1.26$ & 0.53 \\
\hline
\end{tabular}

VAS : visual analogue scale, ODI : Oswestry disability index, BP : bispho sphonate

Table 3. Pedicle screw loosening according to the postoperative periods

\begin{tabular}{lccc} 
& Teriparatide & BP & $p$-value \\
\hline Total number of patients & 33 & 51 & \\
Patients with screw loosening & & & \\
Post-op at 6 months & $4(12)$ & $7(13)$ & 0.831 \\
Post-op at 12 months & $6(18)$ & $13(25)$ & 0.434 \\
Post-op during 6-12 months & $2(6)$ & $6(12)$ & 0.384 \\
Number of screw loosening & & & \\
Post-op at 6 months & $12(6.9)$ & $18(6.8)$ & 0.965 \\
Post-op at 12 months & $16(9.3)$ & $42(16.1)$ & $0.043^{*}$ \\
Post-op during 6-12 months & $4(2.3)$ & $24(9.2)$ & $0.027^{*}$ \\
\hline
\end{tabular}

Values are presented as number (\%). ${ }^{*} p<0.05$. BP : bisphosphonate, Postop : postoperatively 


\section{RESULTS}

The mean ages of the teriparatide and BP groups were 69.45 \pm 7.76 and $66.75 \pm 6.46$ years, and male to female ratios were $8: 25$ and $12: 39$, respectively $(p>0.05)$. The two groups did not significantly different in the presence of diabetes, smoking history, and body mass index ( $p>0.05)$. The number of patients undergoing 1, 2, and 3-level fusion were 16, 14, and three in the teriparatide group, and 27, 19, and five in the BP group. There were no significant differences in the extent of the operation between the two groups ( $p>0.05)$. Preoperative BMD (T-score) in the teriparatide and BP groups were $-3.09 \pm 0.49$ and $-2.94 \pm$ 0.39 , and BMD (T-score) at 12 months after surgery were -2.61 \pm 0.55 and $-2.68 \pm 0.44$, respectively, showing no significant differences between the two groups ( $p>0.05$, Table 1). There was a significant improvement in the BMD (T-score) at 12 months compared to those of the preoperative BMD (T-score) in both groups $(p<0.05)$. The teriparatide group showed a significantly higher degree of improvement in the BMD (T-score) after 12 months $(14.86 \pm 14.97 \%)$ than that of the BP group $(8.55 \pm$ $11.43 \%)(p<0.05$, Table 1). However, the two groups did not show a significant difference in the preoperative and postoperative VAS and ODI ( $p>0.05$, Table 2$)$.

There were no significant differences in the number of patients showing PS loosening at 6 months after surgery between the teriparatide group $(12 \%, 4 / 33)$ and BP group (13\%, 7/51) $(p>0.05)$. At 12 months after surgery, the number of patients with PS loosening was lower in the teriparatide group (18\%, $6 / 33)$ than the BP group $(25 \%, 13 / 51)$, but there was no statistical significance. Between 6 and 12 months after surgery the number of patients showing PS loosening was also lower in the teriparatide group $(6 \%, 2 / 33)$ than the BP group $(12 \%$, $6 / 51)$, but not to a statistically significant degree $(p>0.05$, Table 3). The number of loosened PS at 6 months after surgery was $6.9 \%(12 / 172)$ in the teriparatide group and 6.8\% (18/262) in the BP group without significant difference. However, the number of loosened PS at 12 months after surgery was significantly lower in the teriparatide group $(9.3 \%, 16 / 172)$ than in the BP group $(16.1 \%, 42 / 262)(p<0.05)$. The significant difference in the incidence of PS loosening at 12 months after surgery is thought to be related to the fact that markedly fewer cases of PS loosening occurred in the teriparatide group $(2.3 \%, 4 / 172)$ than in the BP group $(9.2 \%, 24 / 262)$ between 6 and 12 months after surgery $(p<0.05$, Table 3$)$. The mean peri- od of onset of PS loosening was 5.1 \pm 3.1 months after surgery in the teriparatide group and 7.5 \pm 3.2 months after surgery in the BP group $(p<0.05)$. The significantly shorter period for PS loosening occurrence in the teriparatide group also seems to be related to the markedly decreased number of newly developed PS loosening between 6 and 12 months after surgery.

Among teriparatide group, the BMD (T-score) and its degree of improvement after 12 months in the patients without PS loosening were significantly higher $(-2.51 \pm 0.51$ and $17.42 \pm$ $14.42 \%$ ) comparing to those in the patients with PS loosening $(-3.08 \pm 0.47$ and $3.35 \pm 12.52 \%)(p<0.05$, Table 4$)$. The patients

Table 4. Factors for screw loosening in the teriparatide group

\begin{tabular}{lccc}
\hline & $\begin{array}{c}\text { PS loosening } \\
(+)(\mathbf{n}=\mathbf{6})\end{array}$ & $\begin{array}{c}\text { PS loosening }(-) \\
(\mathbf{n}=\mathbf{2 7})\end{array}$ & $\boldsymbol{p}$-value \\
\hline Age (years) & $72.67 \pm 9.07$ & $68.78 \pm 7.44$ & 0.274 \\
Sex (M : F) & $1: 5$ & $7: 20$ & 1.0 \\
DM & 1 & 6 & 1.0 \\
Smoking & 1 & 2 & 0.464 \\
\hline $\begin{array}{l}\text { BMD (T-score), pre- } \\
\text { operative }\end{array}$ & $-3.23 \pm 0.65$ & $-3.06 \pm 0.45$ & 0.426 \\
$\begin{array}{l}\text { BMD (T-score), 12 } \\
\text { months after surgery }\end{array}$ & $-3.08 \pm 0.47$ & $-2.51 \pm 0.51$ & $0.017^{*}$ \\
BMD (T-score) change & $3.35 \pm 12.52$ & $17.42 \pm 14.42$ & $0.035^{*}$ \\
for 12 months (\%) & & & \\
BMI & $25.45 \pm 3.70$ & $23.49 \pm 2.96$ & 0.170 \\
Extent of operation & & & 0.132 \\
1 level & 1 & 15 & \\
2 levels & 4 & 10 & \\
3 levels & 1 & 2 &
\end{tabular}

Low back pain

preoperative

$\begin{array}{lcrr}\text { VAS } & 4.67 \pm 1.75 & 3.96 \pm 1.89 & 0.411 \\ \text { ODI } & 44.33 \pm 10.39 & 43.19 \pm 6.73 & 0.735\end{array}$

Leg pain, preoperative

$\begin{array}{lrrr}\text { VAS } & 6.67 \pm 1.75 & 7.04 \pm 1.09 & 0.507 \\ \begin{array}{l}\text { Low back pain at } 12 \\ \text { months }\end{array} & & & \\ \text { VAS } & 2.83 \pm 0.98 & 2.44 \pm 0.93 & 0.367 \\ \text { ODI } & 21.00 \pm 7.87 & 19.85 \pm 6.25 & 0.700\end{array}$

Leg pain at 12 months

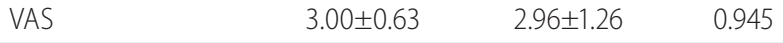

${ }^{*} p<0.05$. PS : pedicle screws, $M$ : male, $F$ : female, DM : diabetes mellitus, BMD : bone mineral density, BMI : body mass index, VAS : visual analogue scale, ODI : Oswestry disability index 
Table 5. Factors for screw loosening in the BP group

\begin{tabular}{|c|c|c|c|}
\hline & PS loosening $(+)(n=13)$ & PS loosening $(-)(n=38)$ & $p$-value \\
\hline Age (years) & $65.54 \pm 6.12$ & $67.16 \pm 6.60$ & 0.441 \\
\hline $\operatorname{Sex}(M: F)$ & $4: 9$ & $8: 30$ & 0.476 \\
\hline DM & 2 & 7 & 0.804 \\
\hline Smoking & 2 & 4 & 0.639 \\
\hline BMD (T-score), pre-operative & $-2.81 \pm 0.25$ & $-2.98 \pm 0.42$ & 0.162 \\
\hline BMD (T-score), 12 months after surgery & $-2.72 \pm 0.28$ & $-2.67 \pm 0.49$ & 0.759 \\
\hline BMD (T-score) change for 12 months (\%) & $3.02 \pm 9.10$ & $10.44 \pm 11.63$ & $0.042^{*}$ \\
\hline BMI & $23.44 \pm 3.26$ & $24.54 \pm 3.09$ & 0.279 \\
\hline Extent of operation & & & 0.256 \\
\hline 1 level & 8 & 19 & \\
\hline 2 levels & 5 & 14 & \\
\hline 3 levels & 0 & 5 & \\
\hline \multicolumn{4}{|l|}{ Low back pain, preoperative } \\
\hline VAS & $5.07 \pm 1.32$ & $4.50 \pm 1.72$ & 0.276 \\
\hline ODI & $41.69 \pm 5.76$ & $45.16 \pm 7.84$ & 0.151 \\
\hline \multicolumn{4}{|l|}{ Leg pain, preoperative } \\
\hline VAS & $6.62 \pm 0.87$ & $6.94 \pm 1.06$ & 0.316 \\
\hline \multicolumn{4}{|l|}{ Low back pain at 12 months } \\
\hline VAS & $3.08 \pm 1.04$ & $3.08 \pm 1.24$ & 0.996 \\
\hline ODI & $19.54 \pm 8.69$ & $23.71 \pm 7.41$ & 0.100 \\
\hline \multicolumn{4}{|l|}{ Leg pain at 12 months } \\
\hline VAS & $3.23 \pm 1.64$ & $3.05 \pm 1.06$ & 0.654 \\
\hline
\end{tabular}

${ }^{*} p<0.05$. BP : bisphosphonate, PS : pedicle screws, $M$ : male, F : female, DM : diabetes mellitus, BMD : bone mineral density, BMI : body mass index, VAS : visual analogue scale, ODI : Oswestry disability index

without PS loosening in the BP group also showed a significantly higher degree of improvement of BMD (T-score), not the BMD (T-score) itself, after 12 months (10.44 $\pm 11.63 \%)$ comparing to the patients with PS loosening (3.02 $\pm 9.10 \%)$ $(p<0.05$, Table 5$)$.

\section{DISCUSSION}

Since its approval by the United States Food and Drug Administration in 2002, teriparatide has been used in patients with osteoporosis to reduce fragility and improve BMD by increasing bone mass ${ }^{29,31)}$. Further, in contrast to BP which efficacy in improving spinal fusion rate and reducing PS loosening is still debated, intermittent use of teriparatide has been verified in several animal studies and clinical trials to increase fusion rates ${ }^{1,22,32,33)}$. Moreover, in a study on postmenopausal patients with osteoporosis who underwent posterolateral spinal fusion, the incidence of PS loosening was significantly lower in the teriparatide group (7-13\%) than in the BP group $(13-26 \%)^{34)}$. It was also true in this study; the patients who were administered teriparatide for 6 months immediately following surgery showed a significantly lower incidence of PS loosening than that of the BP group. Intermittent use of teriparatide not only increases bone mass in cortical and cancellous bones by stimulating bone formation but also improves bone quality by increasing the volume and connectivity of cancellous bone ${ }^{8,18)}$. teriparatide administration initiates stimulation of bone formation after one month and starts to show BMD improvement after 3 months ${ }^{2,17,27,39)}$. Furthermore, after 6 months of teriparatide administration, bone microstructure shows improvement with increased bone volume fraction and 
trabecular number, and risk of fracture begins to decline in patients with osteoporosis ${ }^{13,17,39)}$. In this study, the markedly lower PS loosening between 6 to 12 months after surgery in the teriparatide group compared to that in the BP group is speculated to be related to the temporal outcomes of such pharmacological effects of teriparatide.

Loosening of PS is a delayed postoperative complication that is prevalent among elderly patients with low bone density, which may combine with pseudoarthrosis with instrument failure, adjacent level degeneration, and progressive kyphosis ${ }^{9}$.

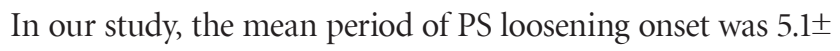
3.1 months post-operatively in the teriparatide group and 7.5 \pm 3.2 months post-operatively in the BP group. The delayed onset in the BP group is a result of a higher incidence of PS loosening after 6 months of surgery in the BP group compared to the teriparatide group. Several studies have revealed that patients begin to show improvement in BMD and bone microstructure and have reduced risk for fracture after 6 months of teriparatide administration ${ }^{13,17,39)}$. In our study, the teriparatide group showed reduced PS loosening incidence after 6 months of the administration, which is comparable with the results of previous studies that stated it took more than 6 months for any visible effects of teriparatide on bone quality to show.

Multiple studies that explored the effects of BP on spinal fusion suggested that BP increases fusion rate ${ }^{4,24,30)}$, but whether $\mathrm{BP}$ reduces PS loosening is still a subject of considerable debate $^{34,42)}$. According to the literature, BP begins to inhibit bone resorption after one month of use and begins to increase BMD after 3-6 months of use. Further, a state of reduced bone turnover is reached after 6 months of BP administration and is maintained until 12 months ${ }^{27)}$. Considering these findings, if BP has any prophylactic effect on PS loosening, the incidence of PS loosening should decline between 6-12 months than the first 6 months of BP use. However, our data showed no significant decrease in the number of patients with PS loosening or the number of loosened PS between the two periods, first 6 months and 6-12 months after surgery. However, we could not confirm such effects of BP as we did not investigate patients who have not received treatment for osteoporosis.

In the papers reporting the efficacy of teriparatide in lumbar spinal fusion, teriparatide administration was initiated 1-2 months before surgery to improve bone density ${ }^{16,34)}$. However, most patients who underwent surgery had not been diagnosed with or treated for osteoporosis before surgery, and surgery could not be delayed due to severe pain. Further, delaying surgery in the presence of severe pain due to degenerative lumbar spine diseases might have resulted in poor results after surgery $^{38)}$. Hence, this study compared patients who were administered teriparatide immediately after surgery to those who used BP immediately after surgery as treatment for osteoporosis among patients who were scheduled to undergo lumbar spinal fusion. Although the therapeutic effects begin to show after 6 months of treatment, we could observe the positive effect of teriparatide reducing PS loosening and more aggressive use of teriparatide would be conducive to better outcome even though osteoporosis was found immediately before surgery.

The teriparatide group showed a significantly higher degree of improvement in the BMD (T-score) than the BP group. However, there was no significant difference in the BMD (Tscore) at 12 months between the two groups. It seemed to be due to the lower, though not significant, preoperative BMD (T-score) in the teriparatide group (-3.09 \pm 0.49$)$ than in the BP group $(-2.94 \pm 0.39)$. We think the reason may be that doctors preferred to use teriparatide in the patients with lower BMD (T-score) rather than BP, and the compliance for the use of teriparatide was also better in the patients with more severe osteoporosis. The patients without PS loosening showed a significantly higher degree of improvement of BMD (T-score) at 12 months comparing to the patients with PS loosening in both groups. Those results suggested that the patients with a better response to anti-osteoporosis medications showed a tendency of a lower incidence of PS loosening.

Teriparatide has been documented to reduce lower back pain in patients with osteoporosis ${ }^{17,39)}$, but there was no difference in VAS or ODI between the teriparatide and BP groups in our study. These results seemed to be mainly due to the lumbar fusion surgery itself already resolved lesions like spinal stenosis or instability causing the pain. In addition, there was no significant difference in VAS or ODI according to the presence of PS loosening in both groups. Although PS loosening may increase lower back pain, previous studies suggested that PS loosening itself not be a determinant of clinical outcomes $^{34,44)}$. However, the PS loosening may exacerbate clinical symptoms or induce pseudoarthrosis in the future, contributing to poor prognosis in the long-term period ${ }^{3,35,45)}$. Whereas the two groups showed a clear difference in the number of loosened PS, the number of patients with PS loosening was not different significantly between the two groups. The small 
sample size and relatively short follow-up period are thought to have contributed to such results.

Our study has limitations of a retrospective study on a relatively small sample size, and we did not compare the data regarding the fusion level. We also did not compare the data with that of a control group who did not receive any treatment for osteoporosis. However, it is practically impossible to set up a control group who has not received any treatment for osteoporosis because osteoporosis drugs are already widely used in the patients with osteoporosis, and any patients diagnosed with osteoporosis should take medications for osteoporosis immediately. Regarding the selection of medication for osteoporosis, we recommended the use of teriparatide first. However, we began the treatment with BP in the patients who refused the use of teriparatide. High price and inconvenience of teriparatide injection seemed to make the patients refuse the teriparatide administration for a long time. Although we got a positive result with 6-month teriparatide reducing PS loosening, teriparatide more than 6 months must be more efficient. Considering that the gap in the incidence of PS loosening between the two groups increased over time, a longer follow-up must be needed.

\section{CONCLUSION}

The use of teriparatide for 6 months starting immediately after lumbar fusion operation seems to reduce PS loosening in the osteoporotic patients. Such preventive effect of teriparatide was apparent after 6 months of administration. We would recommend more active consideration of using teriparatide in the osteoporotic patients planning to receive lumbar fusion surgery.

\section{CONFLICTS OF INTEREST}

No potential conflict of interest relevant to this article was reported.

\section{INFORMED CONSENT}

Informed consent was obtained from all individual participants included in this study.

\section{- Acknowledgements}

This work was supported by the Technology Innovation Program (Advanced Technology Center [ATC], 10048523, Development of fluorography system under 50\% irradiation dose with image quality on par with an giographic equipment to global leader in next generation) funded by the Ministry of Trade, Industry \& Energy (MI, Korea).

\section{References}

1. Abe $Y$, Takahata M, Ito M, Irie K, Abumi K, Minami A : Enhancement of graft bone healing by intermittent administration of human parathyroid hormone (1-34) in a rat spinal arthrodesis model. Bone 41 : 775-785, 2007

2. Arlot M, Meunier PJ, Boivin G, Haddock L, Tamayo J, Correa-Rotter $R$, et al. : Differential effects of teriparatide and alendronate on bone remodeling in postmenopausal women assessed by histomorphometric parameters. J Bone Miner Res 20 : 1244-1253, 2005

3. Bothmann M, Kast E, Boldt GJ, Oberle J : Dynesys fixation for lumbar spine degeneration. Neurosurg Rev 31 : 189-196, 2008

4. Bransford R, Goergens E, Briody J, Amanat N, Cree A, Little D : Effect of zoledronic acid in an L6-L7 rabbit spine fusion model. Eur Spine J 16 : 557-562, 2007

5. Chin DK, Park JY, Yoon YS, Kuh SU, Jin BH, Kim KS, et al. : Prevalence of osteoporosis in patients requiring spine surgery: incidence and significance of osteoporosis in spine disease. Osteoporos Int 18 : 12191224, 2007

6. Cook SD, Salkeld SL, Whitecloud TS 3rd, Barbera J : Biomechanical evaluation and preliminary clinical experience with an expansive pedicle screw design. J Spinal Diso 13 : 230-236, 2000

7. Dakhil-Jerew F, Jadeja H, Cohen A, Shepperd JA : Inter-observer reliability of detecting Dynesys pedicle screw using plain X-rays: a study on 50 post-operative patients. Eur Spine J 18 : 1486-1493, 2009

8. Dempster DW, Cosman F, Kurland ES, Zhou H, Nieves J, Woelfert L, et al. : Effects of daily treatment with parathyroid hormone on bone microarchitecture and turnover in patients with osteoporosis: a paired biopsy study. J Bone Miner Res 16 : 1846-1853, 2001

9. DeWald CJ, Stanley T : Instrumentation-related complications of multilevel fusions for adult spinal deformity patients over age 65: surgical considerations and treatment options in patients with poor bone quality. Spine (Phila Pa 1976) 31(19 Suppl) : S144-S151, 2006

10. Fisher JE, Rogers MJ, Halasy JM, Luckman SP, Hughes DE, Masarachia PJ, et al. : Alendronate mechanism of action: geranylgeraniol, an intermediate in the mevalonate pathway, prevents inhibition of osteoclast formation, bone resorption, and kinase activation in vitro. Proc Natl Acad Sci U S A 96 : 133-138, 1999

11. Flahiff $C M$, Gober GA, Nicholas RW : Pullout strength of fixation screws from polymethylmethacrylate bone cement. Biomaterials 16 : 533 536, 1995 
12. Gaines RW Jr : The use of pedicle-screw internal fixation for the operative treatment of spinal disorders. J Bone Joint Surg Am 82 : 14581458, 2000

13. Graeff C, Timm W, Nickelsen TN, Farrerons J, Marín F, Barker C, et al. : Monitoring teriparatide-associated changes in vertebral microstructure by high-resolution CT in vivo: results from the EUROFORS study. J Bone Miner Res 22 : 1426-1433, 2007

14. Halvorson TL, Kelley LA, Thomas KA, Whitecloud TS 3rd, Cook SD : Effects of bone mineral density on pedicle screw fixation. Spine (Phila Pa 1976) 19 : 2415-2420, 1994

15. Heinemann DF : Osteoporosis. An overview of the National Osteoporosis Foundation clinical practice guide. Geriatrics 55 : 31-36; quiz 39, 2000

16. Inoue G, Ueno M, Nakazawa T, Imura T, Saito W, Uchida K, et al. : Teriparatide increases the insertional torque of pedicle screws during fusion surgery in patients with postmenopausal osteoporosis: Clinical article. J Neurosurg Spine 21 : 425-431, 2014

17. Jakob F, Oertel $H$, Langdahl B, Ljunggren $O$, Barrett $A$, Karras $D$, et al. : Effects of teriparatide in postmenopausal women with osteoporosis pretreated with bisphosphonates: 36 -month results from the European Forsteo Observational Study. Eur J Endocrinol 166 : 87-97, 2012

18. Jiang Y, Zhao JJ, Mitlak BH, Wang O, Genant HK, Eriksen EF : Recombinant human parathyroid hormone (1-34) [teriparatide] improves both cortical and cancellous bone structure. J Bone Miner Res 18 : 19321941, 2003

19. Kanis JA : Diagnosis of osteoporosis and assessment of fracture risk. Lancet 359 : 1929-1936, 2002

20. Keaveny TM, Donley DW, Hoffmann PF, Mitlak BH, Glass EV, San Martin $J A$ : Effects of teriparatide and alendronate on vertebral strength as assessed by finite element modeling of QCT scans in women with osteoporosis. J Bone Miner Res 22 : 149-157, 2007

21. Lee JH, Lee JH, Park JW, Shin YH : The insertional torque of a pedicle screw has a positive correlation with bone mineral density in posterior lumbar pedicle screw fixation. J Bone Joint Surg Br 94 : 93-97, 2012

22. Lehman RA Jr, Dmitriev AE, Cardoso MJ, Helgeson MD, Christensen $C L$, Raymond JW, et al. : Effect of teriparatide $[\operatorname{rhPTH}(1,34)]$ and calcitonin on intertransverse process fusion in a rabbit model. Spine (Phila Pa 1976) 35 : 146-152, 2010

23. Lehman RA Jr, Kang DG, Wagner SC : Management of osteoporosis in spine surgery. J Am Acad Orthop Surg 23 : 253-263, 2015

24. Lehman RA Jr, Kuklo TR, Freedman BA, Cowart JR, Mense MG, Riew $K D$ : The effect of alendronate sodium on spinal fusion: a rabbit model. Spine J 4 : 36-43, 2004

25. Lei $\mathbf{W}, \mathrm{Wu} Z$ : Biomechanical evaluation of an expansive pedicle screw in calf vertebrae. Eur Spine J 15 : 321-326, 2006

26. Luk KD, Chen L, Lu WW : A stronger bicortical sacral pedicle screw fixation through the s1 endplate: an in vitro cyclic loading and pull-out force evaluation. Spine (Phila Pa 1976) 30 : 525-529, 2005

27. McClung MR, San Martin J, Miller PD, Civitelli R, Bandeira F, Omizo M, et al. : Opposite bone remodeling effects of teriparatide and alendronate in increasing bone mass. Arch Intern Med 165 : 1762-1768, 2005
28. Moore DC, Maitra RS, Farjo LA, Graziano GP, Goldstein SA : Restoration of pedicle screw fixation with an in situ setting calcium phosphate cement. Spine (Phila Pa 1976) 22 : 1696-1705, 1997

29. Murad MH, Drake MT, Mullan RJ, Mauck KF, Stuart LM, Lane MA, et al. : Clinical review. Comparative effectiveness of drug treatments to prevent fragility fractures: a systematic review and network meta-analysis. J Clin Endocrinol Metab 97 : 1871-1880, 2012

30. Nagahama K, Kanayama M, Togawa D, Hashimoto T, Minami A : Does alendronate disturb the healing process of posterior lumbar interbody fusion? A prospective randomized trial: clinical article. J Neurosurg Spine 14 : 500-507, 2011

31. Neer RM, Arnaud CD, Zanchetta JR, Prince R, Gaich GA, Reginster JY, et al. : Effect of parathyroid hormone (1-34) on fractures and bone mineral density in postmenopausal women with osteoporosis. N Engl J Med 344 : 1434-1441, 2001

32. O'Loughlin PF, Cunningham ME, Bukata SV, Tomin E, Poynton AR, Doty $S B$, et al. : Parathyroid hormone (1-34) augments spinal fusion, fusion mass volume, and fusion mass quality in a rabbit spinal fusion model. Spine (Phila Pa 1976) 34 : 121-130, 2009

33. Ohtori S, Inoue G, Orita S, Yamauchi K, Eguchi Y, Ochiai N, et al. : Teriparatide accelerates lumbar posterolateral fusion in women with postmenopausal osteoporosis: prospective study. Spine (Phila Pa 1976) 37 : E1464-E1468, 2012

34. Ohtori S, Inoue G, Orita S, Yamauchi K, Eguchi Y, Ochiai N, et al. : Comparison of teriparatide and bisphosphonate treatment to reduce pedicle screw loosening after lumbar spinal fusion surgery in postmenopausal women with osteoporosis from a bone quality perspective. Spine (Phila Pa 1976) 38 : E487-E492, 2013

35. Okuyama K, Abe E, Suzuki T, Tamura Y, Chiba M, Sato K : Can insertional torque predict screw loosening and related failures? An in vivo study of pedicle screw fixation augmenting posterior lumbar interbody fusion. Spine (Phila Pa 1976) $25: 858-864,2000$

36. Ozawa T, Takahashi K, Yamagata M, Ohtori S, Aoki Y, Saito T, et al. : Insertional torque of the lumbar pedicle screw during surgery. J Orthop Sci 10 : 133-136, 2005

37. Pfeiffer M, Gilbertson LG, Goel VK, Griss P, Keller JC, Ryken TC, et al. : Effect of specimen fixation method on pullout tests of pedicle screws. Spine (Phila Pa 1976) 21 : 1037-1044, 1996

38. Quon JA, Sobolev BG, Levy AR, Fisher CG, Bishop PB, Kopec JA, et al. : The effect of waiting time on pain intensity after elective surgical lumbar discectomy. Spine J 13 : 1736-1748, 2013

39. Rajzbaum G, Grados F, Evans D, Liu-Leage S, Petto H, Augendre-Ferrante $B$ : Treatment persistence and changes in fracture risk, back pain, and quality of life amongst patients treated with teriparatide in routine clinical care in France: results from the European Forsteo Observational Study. Joint Bone Spine 81 : 69-75, 2014

40. Sandén $B$, Olerud $C$, Petrén-Mallmin $M$, Johansson $C$, Larsson $S$ : The significance of radiolucent zones surrounding pedicle screws. Definition of screw loosening in spinal instrumentation. J Bone Joint Surg Br 86 : 457-461, 2004

41. Sawakami K, Yamazaki A, Ishikawa S, Ito T, Watanabe K, Endo N : Poly- 
methylmethacrylate augmentation of pedicle screws increases the initial fixation in osteoporotic spine patients. J Spinal Disord Tech 25 : E28E35, 2012

42. Tu CW, Huang KF, Hsu HT, Li HY, Yang SS, Chen YC : Zoledronic acid infusion for lumbar interbody fusion in osteoporosis. J Surg Res 192 : $112-116,2014$

43. Wray S, Mimran R, Vadapalli S, Shetye SS, McGilvray KC, Puttlitz CM : Pedicle screw placement in the lumbar spine: effect of trajectory and screw design on acute biomechanical purchase. J Neurosurg Spine
22 : 503-510, 2015

44. Wu J, Huang W, Tsai H, Ko C, Wu C, Tu T, et al. : Pedicle screw loosening in dynamic stabilization: incidence, risk, and outcome in 126 patients. Neurosurg Focus 31 : E9, 2011

45. Wu ZX, Gong FT, Liu L, Ma ZS, Zhang Y, Zhao X, et al. : A comparative study on screw loosening in osteoporotic lumbar spine fusion between expandable and conventional pedicle screws. Arch Orthop Trauma Surg 132 : 471-476, 2012 